\title{
GMR
}

\section{Effect of Astragalus polysaccharides on ovariectomy-induced osteoporosis in mice}

\author{
J. Huo and X. Sun \\ Department of Pharmacy, Wuxi No. 2 People's Hospital, Wuxi, Jiangsu, China \\ Corresponding author: X. Sun \\ E-mail: sunxinwx@163.com
}

Genet. Mol. Res. 15 (4): gmr15049169

Received September 5, 2016

Accepted October 14, 2016

Published December 19, 2016

DOI http://dx.doi.org/10.4238/gmr15049169

Copyright (C) 2016 The Authors. This is an open-access article distributed under the terms of the Creative Commons Attribution ShareAlike (CC BY-SA) 4.0 License.

\begin{abstract}
Postmenopausal osteoporosis, a common type of osteoporosis in women, has become a serious public health issue. Astragalus polysaccharides (APS), possessing various pharmacological activities, are the active ingredients of Radix Astragali. It can be advantageous in the treatment of postmenopausal osteoporosis. In the present study, we evaluated the potential therapeutic effects of APS on postmenopausal osteoporosis by using a mice model induced by ovariectomy (OVX). Forty-eight female 6-week-old outbred ICR mice were randomly divided into six groups $(\mathrm{N}=8)$ : Sham group, OVX group, $17 \beta$-estradiol (E2, $0.1 \mathrm{mg} / \mathrm{kg}$ )-treated OVX group, and APS (at three doses: 100, 200, and $400 \mathrm{mg} / \mathrm{kg}$ )-treated OVX groups. The effect of APS on the bone mineral density (BMD) was determined using dualenergy X-ray absorptiometry. The serum levels of receptor activator of nuclear factor kappa-B ligand (RANKL), osteoprotegerin (OPG), osteocalcin, and tumor necrosis factor (TNF)- $\alpha$ were measured using ELISA kits. The results revealed that APS exerted significant antiosteoporotic activity by increasing the BMD considerably in a dosedependent manner. APS treatment reduced the serum RANKL levels
\end{abstract}


considerably and increased the serum OPG levels, thereby lowering the ratio of RANKL/OPG. Furthermore, APS also markedly reduced osteocalcin and TNF- $\alpha$ concentration in OVX-induced postmenopausal osteoporosis mice model. These results showed that APS exerts a protective effect on bone loss in OVX mice. The molecular mechanism underlying this effect be the reduction of bone resorption and inhibition of osteoclastogenesis. Our findings suggest that APS may be a potential strategy for the prevention and treatment of postmenopausal osteoporosis.

Key words: Osteoporosis; Astragalus polysaccharides; Osteoprotegerin; Receptor activator of nuclear factor kappa-B ligand

\section{INTRODUCTION}

Osteoporosis is a systemic bone disease characterized by the reduction in bone tissue content and alteration of bone microstructure (Klibanski et al., 2001), which increases bone fragility and reduces bone strength, thereby tending to increase the risk of fracture resulting in significant morbidity and mortality (Raisz, 2005; Jackson and Mysiw, 2014). There are two types of primary osteoporosis: postmenopausal osteoporosis (Primary type 1 osteoporosis) and senile osteoporosis (Primary type 2 osteoporosis). Postmenopausal osteoporosis, which is the most common type in women, has become a serious public health issue resulting in increased morbidity, mortality, and high health-care cost (Kanis, 1994). Postmenopausal osteoporosis is associated with estrogen deficiency, which induces osteoclast formation, thereby resulting in an imbalance between osteoblasts and osteoclasts (Lerner, 2006). Various drugs, including estrogen, bisphosphonates, fluoride, and calcitonin, have been used for the clinical treatment of postmenopausal osteoporosis. However, these agents have been reported to have side effects, which limit their use. Thus, an increasing number of research studies have focused on the use of natural compounds for osteoporosis treatment owing to their various bioactivities (Wang et al., 2015).

Radix Astragali, the dried root of Astragalus membranaceus (Fisch.) Bunge, is a herb used in traditional Chinese medicine. Previous studies have reported that Radix Astragali extracts showed estrogenic activity in vitro (Zhang et al., 2005) and prevented bone loss in ovariectomized (OVX) rats (Kim et al., 2003). Recently, it has been shown that the combination of Rubus coreanus Miquel and A. membranaceus Bunge extracts prevented tibial bone loss and improved bone biomechanical properties in OVX-induced osteoporosis in mice (Jung Koo et al., 2014). Astragalus polysaccharide (APS) is one of the active ingredients of Radix Astragali. It has been shown to exert various pharmacological activities, including antiinflammatory (Luo et al., 2015; Wei et al., 2016), antioxidant (Li et al., 2010; Yan et al., 2010), anti-diabetic (Liu et al., 2013), and anti-tumor activity (Yang et al., 2013). Furthermore, APS treatment ameliorated adjuvant-induced arthritis in rats in a dose-dependent manner (Jiang et al., 2010). Additionally, there has been an increasing interest on the effect of polysaccharides extracted from medicinal plants for the treatment of osteoporosis (Zeng et al., 2011; Wang et al., 2013; Chen et al., 2015). However, the anti-osteoporotic effects of APS on postmenopausal osteoporosis have not been studied. Thus, the aim of the current study was to investigate the effect of APS on OVX-induced osteoporosis in mice and to explore its underlying molecular mechanism. In this study, we examined the effects of APS on bone metabolism by using a mice model of OVX-induced osteoporosis.

Genetics and Molecular Research 15 (4): gmr15049169 


\section{MATERIAL AND METHODS}

\section{Animals}

Forty-eight female 6-week-old outbred Institute of Cancer Research (ICR) strain mice (weighing 20-22 g) were purchased from the Experimental Animal Center of Nanjing Medical University (Nanjing, China). The animals were provided ad libitum access to sterile standard mouse chow and water for the duration of this study. They were housed at room temperature $\left(22^{\circ} \pm 2^{\circ} \mathrm{C}\right)$ with a relative humidity $(55 \pm 5 \%)$ under a normal $12 \mathrm{~h}$ light $/ 12 \mathrm{~h}$ dark cycle. The animal studies were carried out in accordance with the National Institute of Health Guidelines for the Care and Use of Laboratory Animals.

\section{Postmenopausal osteoporosis induced using OVX}

After 1 week of acclimation, the ICR mice were randomly divided into six groups $(\mathrm{N}=8)$ : Sham group, OVX group, $17 \beta$-estradiol (E2, $0.1 \mathrm{mg} / \mathrm{kg})$-treated OVX group, and APS (at three doses: 100, 200, and $400 \mathrm{mg} / \mathrm{kg}$ )-treated OVX groups. After the mice were anesthetized with $10 \%$ chloral hydrate solution, the OVX+E2 and OVX+APS groups were subjected to OVX operation, whereas the Sham control group was subjected to a sham surgery. The animals were allowed to recover from the surgery for 5 days prior to the experiments. Then, the mice in the OVX+APS groups were subcutaneously injected with APS (100, 200, and $400 \mathrm{mg} / \mathrm{kg}$ ) daily for 12 weeks, while those in the OVX+E2 group were injected with 17 $\beta$-estradiol three times per week for 12 weeks. The mice in the Sham and OVX groups were treated with PBS containing $0.1 \%$ dimethyl sulfoxide as the vehicle. The APS used in this study was a sterile, injectable extract of $A$. membranaceus (PhytoHealth, Taipei, Taiwan). At the end of the treatment, the animals were killed after the blood collection. The serum samples were collected and stored at $-80^{\circ} \mathrm{C}$ for biochemical analysis.

\section{Bone mineral density (BMD) analysis}

The right femur samples of all the groups were scanned in a desktop cone beam microCT ( $\mu$ CT80; Scanco Medical, Brüttisellen, Switzerland) and detected using the supplied software ( $\mu$ CT80 Evaluation Program v. 6.5-1; Scanco Medical). The BMD (mg/cm $)$ and relative bone volume $(\mathrm{BV} / \mathrm{TV}, \%)$ of the right femur were measured.

\section{Biochemical analysis of serum samples}

The serum was separated via centrifugation at $1500 \mathrm{~g}$ for $10 \mathrm{~min}$ at $4^{\circ} \mathrm{C}$. The serum concentrations of bone turnover markers were measured using ELISA kits for receptor activator of nuclear factor kappa-B ligand (RANKL) and osteoprotegerin (OPG) (R\&D Systems, Minneapolis, MN, USA), osteocalcin (Biomedical Technologies Inc., Stoughton, MA, USA), and tumor necrosis factor (TNF)- $\alpha$ (Immuno-Biological Laboratories Inc., Minneapolis, MN, USA) according to the manufacturers' instructions.

\section{Statistical analysis}

Data are reported as means $\pm \mathrm{SD}$. Statistical analysis was performed using one-way analysis of variance (ANOVA), followed by a post hoc least significant difference test. $\mathrm{P}<$ 0.05 was considered significant. 


\section{RESULTS}

\section{Body and uterine weight}

There were no significant differences in the initial body weights between the Sham, OVX, and APS-treated OVX groups (Figure 1A). Twelve weeks after the surgery, the final body weight of the OVX group increased noticeably in comparison to that of the Sham group $(\mathrm{P}<0.01)$. However, APS treatment significantly reduced the OVX-induced weight gain at $200(\mathrm{P}<0.05)$ and $400 \mathrm{mg} / \mathrm{kg}(\mathrm{P}<0.01)$. Furthermore, the uterine weights of the OVX group reduced considerably when compared to those of the Sham group $(\mathrm{P}<0.001)$. However, the uterine weights of the APS group $(400 \mathrm{mg} / \mathrm{kg}$ ) were significantly higher than those of the OVX group were $(\mathrm{P}<0.05$; Figure $1 \mathrm{~B})$.

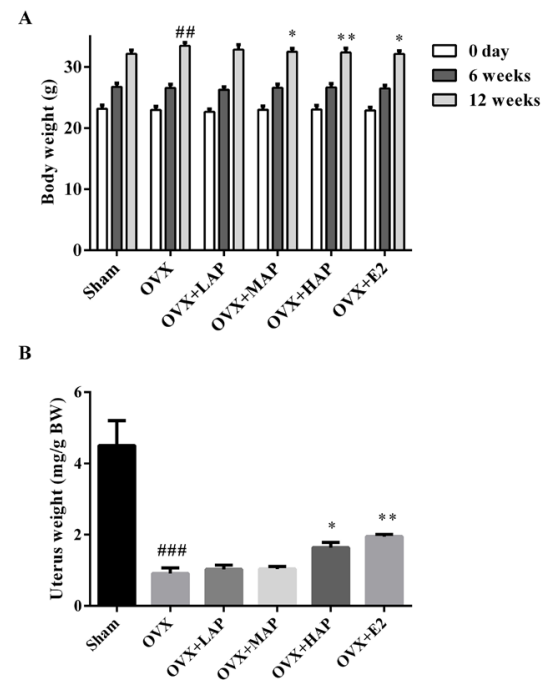

Figure 1. Effect of APS on body and uterine weight in ovariectomized (OVX) mice. The body weight changes (A) and uterine wet weight $(\mathbf{B})$ were measured. The results are reported as means \pm SD. ${ }^{\#} \mathrm{P}<0.01$ vs Sham group; $\mathrm{P}$ $<0.001$ vs Sham group; ${ }^{*} \mathrm{P}<0.05$ vs OVX group; $* * \mathrm{P}<0.01$ vs OVX group. LAP: low-dose APS (100 mg $\left./ \mathrm{kg}\right)-$ treated OVX group, MAP: medium-dose APS (200 mg/kg)-treated OVX group; HAP: high-dose APS (400 mg/ $\mathrm{kg}$ )-treated OVX group.

\section{Effects of APS on bone morphometric parameters in OVX mice}

To investigate the anti-osteoporotic effect of APS in OVX mice, the BV/TV, BMD and bone microarchitecture of the right femur were determined. The BV/TV and BMD significantly decreased in the OVX group compared with those in the Sham group $(\mathrm{P}<0.001$; Figure 2A-B). However, APS treatment considerably increased BV/TV and BMD in a dosedependent manner $(100 \mathrm{mg} / \mathrm{kg}: \mathrm{P}<0.05 ; 200 \mathrm{mg} / \mathrm{kg}: \mathrm{P}<0.01 ; 400 \mathrm{mg} / \mathrm{kg}: \mathrm{P}<0.001)$, and no significant difference was observed in BMD between the APS $(400 \mathrm{mg} / \mathrm{kg})$ and E2 groups (P $>0.05$; Figure 2A-B). Moreover, the treatment of APS and E2 significantly inhibited bone loss in the OVX mice (Figure 2C). 

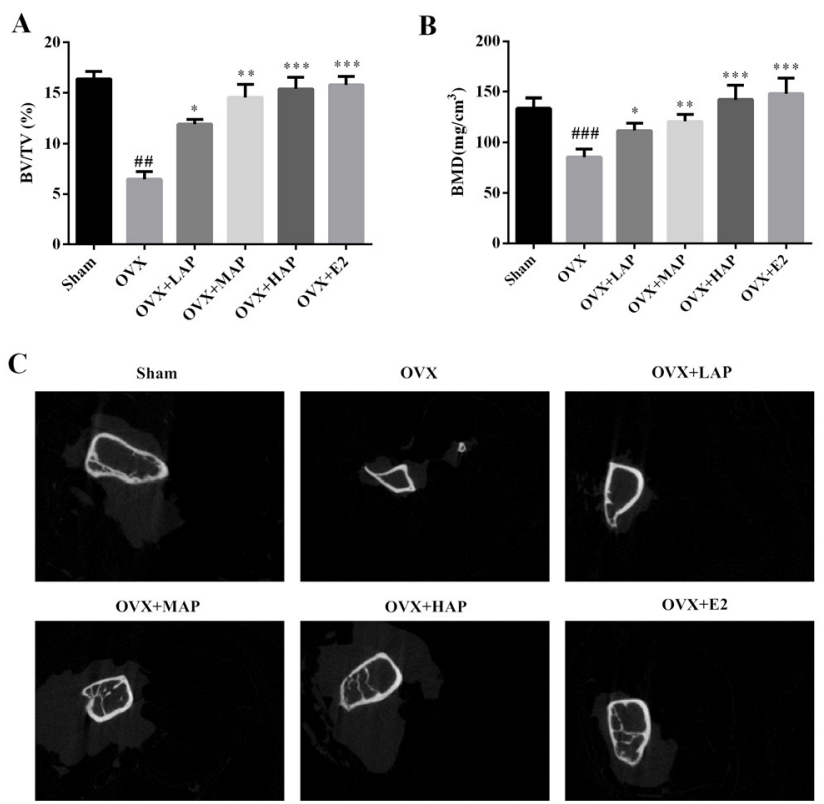

Figure 2. Effects of APS on bone morphometric parameters in OVX mice. After the 12-week APS treatment, the femurs were dissected free of soft tissues. The BV/TV (A) and BMD (B) of the femur were measured using the micro-CT software. C. Two-dimensional images show the changes in the femoral microarchitecture in mice. The results are reported as means $\pm \mathrm{SD}$. ${ }^{\# *} \mathrm{P}<0.001$ vs Sham group; ${ }^{*} \mathrm{P}<0.05$ vs $\mathrm{OVX}$ group; ${ }^{*} * \mathrm{P}<0.01$ vs $\mathrm{OVX}$ group; ***P $<0.001$ vs OVX group. LAP: low-dose APS $(100 \mathrm{mg} / \mathrm{kg})$-treated OVX group, MAP: medium-dose APS (200 mg/kg)-treated OVX group; HAP: high-dose APS (400 mg/kg)-treated OVX group.

\section{Effect of APS on serum RANKL and OPG levels as well as on the RANKL/OPG ratio in OVX mice}

To investigate the effects of the 12-week APS treatment on osteoclast regulation, we measured the serum RANKL and OPG levels by using commercial ELISA kits. In the OVX mice, the serum levels of RANKL markedly increased $(\mathrm{P}<0.001$; Figure 3A-B), whereas the serum levels of OPG decreased when compared with those in the Sham group $(\mathrm{P}<0.001)$. APS treatment considerably decreased the serum RANKL levels $(100 \mathrm{mg} /$ $\mathrm{kg}: \mathrm{P}<0.05 ; 200$ and $400 \mathrm{mg} / \mathrm{kg}: \mathrm{P}<0.01)$ and increased the serum OPG levels $(200$ and $400 \mathrm{mg} / \mathrm{kg}$ : $\mathrm{P}<0.05)$. Therefore, the increase in RANK/OPG ratio in the OVX group $(\mathrm{P}<$ $0.001)$ was significantly decreased by APS treatment $(100 \mathrm{mg} / \mathrm{kg}: \mathrm{P}<0.05 ; 200$ and 400 $\mathrm{mg} / \mathrm{kg}$ : $\mathrm{P}<0.01)$. In addition, the treatment of APS had a comparable effect in reducing the ratio of RANK/OPG in OVX mice.

\section{Effect of APS on the serum levels of osteocalcin and TNF- $\alpha$ in OVX mice}

Since osteocalcin and TNF- $\alpha$ play a crucial role in bone turnover, we determined the serum concentrations of osteocalcin and TNF- $\alpha$ in OVX mice. The serum concentrations of osteocalcin in the OVX group were significantly higher than those in the Sham group were (P $<0.001$; Figure 4). Moreover, the serum TNF- $\alpha$ levels increased considerably in OVX mice 
when than those in the Sham group $(\mathrm{P}<0.001)$. However, the treatment of APS effectively reduced OVX-induced elevation of serum osteocalcin $(200 \mathrm{mg} / \mathrm{kg}: \mathrm{P}<0.05 ; 400 \mathrm{mg} / \mathrm{kg}$ : $\mathrm{P}<$ $0.01)$ and TNF- $\alpha$ levels (200 and $400 \mathrm{mg} / \mathrm{kg}: \mathrm{P}<0.01)$.
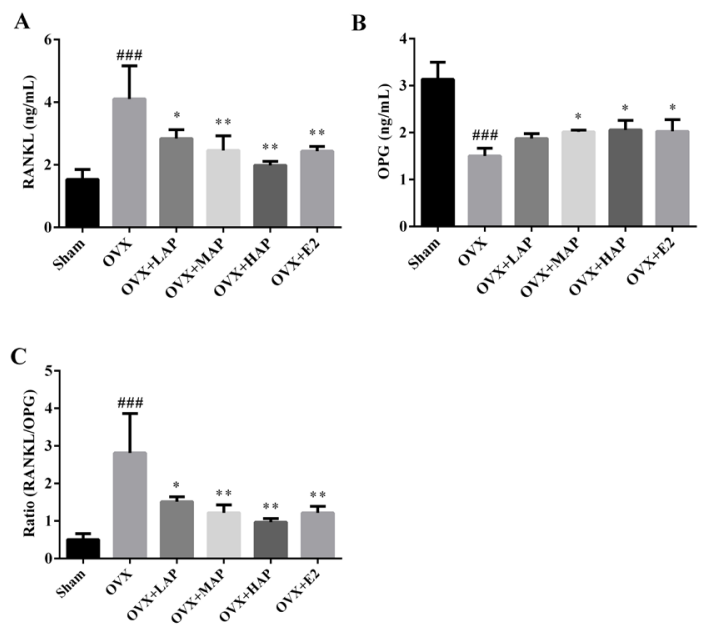

Figure 3. Effects of APS on OPG and RANKL levels in the serum as well as the RANK/OPG ratio in OVX mice. RANKL (A) and OPG (B) in the serum were determined using ELISA and the RANKL/OPG ratio (C) was calculated. The results are reported as means $\pm \mathrm{SD} .{ }^{\# *} \mathrm{P}<0.001$ vs Sham group; $* \mathrm{P}<0.05$ vs OVX group; **P $<$ 0.01 vs OVX group. LAP: low-dose APS (100 mg/kg)-treated OVX group, MAP: medium-dose APS (200 mg/kg)treated OVX group; HAP: high-dose APS (400 mg/kg)-treated OVX group.
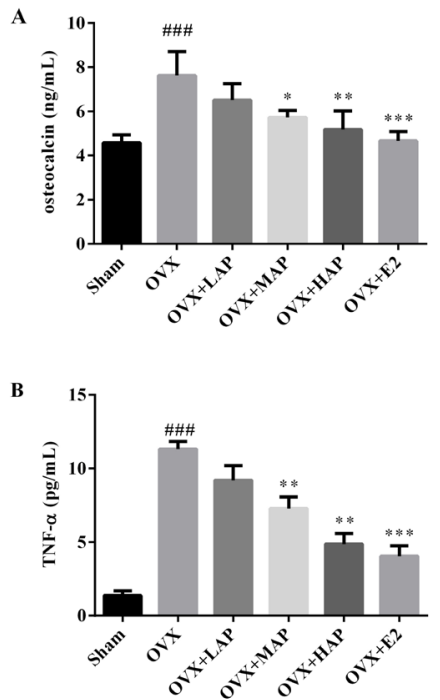

Figure 4. Effects of APS on the serum levels of osteocalcin and TNF- $\alpha$ in OVX mice. Osteocalcin (A) and TNF- $\alpha$ (B) levels were determined using ELISA. The results are reported as means $\pm \mathrm{SD}$. ${ }^{\# \#} \mathrm{P}<0.001$ vs Sham group; ${ }^{*} \mathrm{P}$ $<0.05$ vs OVX group; ${ }^{*} \mathrm{P}<0.01$ vs OVX group; $* * * \mathrm{P}<0.001$ vs OVX group. LAP: low-dose APS (100 mg/kg)treated OVX group, MAP: medium-dose APS (200 mg/kg)-treated OVX group; HAP: high-dose APS (400 mg/ $\mathrm{kg}$ )-treated OVX group.

Genetics and Molecular Research 15 (4): gmr15049169 


\section{DISCUSSION}

In this study, we investigated the effect of APS on OVX-induced osteoporosis in mice. The results showed that the mean uterine weight of the OVX group was significantly lower than that of the Sham group. Although the administration of APS increased the uterine weight compared to that of the OVX group, it was still lower than that of the Sham group. Furthermore, a previous study showed that the body weight gain in OVX rats increased significantly compared with that in the Sham rats (Omi and Ezawa, 1995). In line with this study, we found that the OVX group showed a significant increase in body weight gain than the Sham group did. Furthermore, the results of study showed that APS treatment significantly prevented body weight gain and uterine weight loss induced by OVX. In addition, we found that OVX surgery significantly decreased the BMD. However, APS treatment increased the BMD of the right femur significantly, which indicated the anti-osteoporotic effect of APS in OVX mice.

It is widely recognized that the OPG/RANK/RANKL signaling pathway plays a key role in the balance between bone formation and resorption (Boyce and Xing, 2007; Giner et al., 2009). The binding of RANKL to RANK stimulates the maturation and activation of osteoclasts resulting in the activation of signaling pathways that regulate osteoclast function. OPG negatively regulates RANKL binding to RANK in order to decrease bone resorption, and it acts as a decoy receptor for RANKL (Wada et al., 2006). In this study, we observed that in the OVX mice, the serum levels of RANKL increased markedly, whereas the serum OPG levels decreased when compared to those in the Sham group. However, APS treatment restored the levels of biochemical markers related to bone metabolism by increasing the production of OPG and downregulating the expression of RANKL in OVX mice, which suggests that APS may ameliorate OVX-induced bone loss by reducing bone resorption.

Serum osteocalcin is a diagnostic biomarker for primary osteoporosis in women (Singh et al., 2015). It is secreted by osteoblasts during the formative phase of bone remodeling (Civitelli et al., 2009). In osteoporosis, pro-inflammatory cytokines, such as TNF- $\alpha$, promote osteoclastogenesis and inhibit osteoblastogenesis. Jagtap et al. (2011) reported that the mean serum level of osteocalcin was significantly elevated in patients with postmenopausal osteoporosis when compared with that in healthy controls. Moreover, it was reported in a previous study that a mixture containing $R$. coreanus Miquel and $A$. membranaceus Bunge extracts helped in the recovery of serum osteocalcin and TNF- $\alpha$ levels in OVX mice (Jung Koo et al., 2014). In the present study, we found that the serum concentrations of osteocalcin and TNF- $\alpha$ in the OVX group were significantly higher than those in the Sham group. However, there was a significant decrease in the serum concentrations of osteocalcin and TNF- $\alpha$ in the APS-treated mice. These results further confirmed the anti-osteoporotic effects of APS in mice, and the mechanism underlying this effect may be associated with the inhibition of osteoclastogenesis by reducing the serum osteocalcin and TNF- $\alpha$ levels.

In conclusion, the present study showed the anti-osteoporotic effect of APS in OVX mice. APS increased the BMD in OVX mice; the mechanism underlying this effect may be associated with the reduction in bone resorption by the modulation of RANKL/OPG ratio and the inhibition of osteoclastogenesis by reducing serum osteocalcin and TNF- $\alpha$ levels in OVX mice. Therefore, we suggest that APS may be a potential strategy for the prevention and treatment of postmenopausal osteoporosis. However, further study is required to investigate the mechanism by which APS modulates RANKL/OPG.

Genetics and Molecular Research 15 (4): gmr15049169 


\section{Conflicts of interest}

The authors declare no conflict of interest.

\section{REFERENCE}

Boyce BF and Xing L (2007). The RANKL/RANK/OPG pathway. Curr. Osteoporos. Rep. 5: 98-104. http://dx.doi. org/10.1007/s11914-007-0024-y

Chen C, Qin Y, Fang JP, Ni XY, et al. (2015). WSS25, a sulfated polysaccharide, inhibits RANKL-induced mouse osteoclast formation by blocking SMAD/ID1 signaling. Acta Pharmacol. Sin. 36: 1053-1064. http://dx.doi. org/10.1038/aps.2015.65

Civitelli R, Armamento-Villareal R and Napoli N (2009). Bone turnover markers: understanding their value in clinical trials and clinical practice. Osteoporos. Int. 20: 843-851. http://dx.doi.org/10.1007/s00198-009-0838-9

Giner M, Rios MA, Montoya MA, Vázquez MA, et al. (2009). RANKL/OPG in primary cultures of osteoblasts from postmenopausal women. Differences between osteoporotic hip fractures and osteoarthritis. J. Steroid Biochem. Mol. Biol. 113: 46-51. http://dx.doi.org/10.1016/j.jsbmb.2008.11.005

Jackson RD and Mysiw WJ (2014). Insights into the epidemiology of postmenopausal osteoporosis: the Women's Health Initiative. Semin. Reprod. Med. 32: 454-462.http://dx.doi.org/10.1055/s-0034-1384629

Jagtap VR, Ganu JV and Nagane NS (2011). BMD and serum intact osteocalcin in postmenopausal osteoporosis women. Indian J. Clin. Biochem. 26: 70-73.http://dx.doi.org/10.1007/s12291-010-0074-2

Jiang JB, Qiu JD, Yang LH, He JP, et al. (2010). Therapeutic effects of Astragalus polysaccharides on inflammation and synovial apoptosis in rats with adjuvant-induced arthritis. Int. J. Rheum. Dis. 13: 396-405.http://dx.doi.org/10.1111/ j.1756-185X.2010.01555.X

Jung Koo H, Sohn EH, Kim YJ, Jang SA, et al. (2014). Effect of the combinatory mixture of Rubus coreanus Miquel and Astragalus membranaceus Bunge extracts on ovariectomy-induced osteoporosis in mice and anti-RANK signaling effect. J. Ethnopharmacol. 151: 951-959.http://dx.doi.org/10.1016/j.jep.2013.12.008

Kanis JA; WHO Study Group (1994). Assessment of fracture risk and its application to screening for postmenopausal osteoporosis: synopsis of a WHO report. Osteoporos. Int. 4: 368-381. http://dx.doi.org/10.1007/BF01622200

Kim C, Ha H, Lee JH, Kim JS, et al. (2003). Herbal extract prevents bone loss in ovariectomized rats. Arch. Pharm. Res. 26: 917-924.http://dx.doi.org/10.1007/BF02980200

Klibanski A, Adams-Campbell L, Bassford TL, Blair SN, et al.; NIH Consensus Development Panel on Osteoporosis Prevention, Diagnosis, and Therapy (2001). Osteoporosis prevention, diagnosis, and therapy. JAMA 285: 785-795. http://dx.doi.org/10.1001/jama.285.6.785

Lerner UH (2006). Bone remodeling in post-menopausal osteoporosis. J. Dent. Res. 85: 584-595. http://dx.doi. org/10.1177/154405910608500703

Li R, Chen WC, Wang WP, Tian WY, et al. (2010). Antioxidant activity of Astragalus polysaccharides and antitumour activity of the polysaccharides and siRNA. Carbohydr. Polym. 82: 240-244. http://dx.doi.org/10.1016/j. carbpol.2010.02.048

Liu M, Qin J, Hao Y, Liu M, et al. (2013). Astragalus polysaccharide suppresses skeletal muscle myostatin expression in diabetes: involvement of ROS-ERK and NF-kB pathways. Oxid. Med. Cell. Longev. 2013: 782497.http://dx.doi. org $/ 10.1155 / 2013 / 782497$

Luo T, Qin J, Liu M, Luo J, et al. (2015). Astragalus polysaccharide attenuates lipopolysaccharide-induced inflammatory responses in microglial cells: regulation of protein kinase B and nuclear factor-kB signaling. Inflamm. Res. 64: 205212.http://dx.doi.org/10.1007/s00011-015-0798-9

Omi N and Ezawa I (1995). The effect of ovariectomy on bone metabolism in rats. Bone 17 (Suppl): 163S-168S. http:// dx.doi.org/10.1016/8756-3282(95)00329-C

Raisz LG (2005). Pathogenesis of osteoporosis: concepts, conflicts, and prospects. J. Clin. Invest. 115: 3318-3325. http:// dx.doi.org/10.1172/JCI27071

Singh S, Kumar D and Lal AK (2015). Serum osteocalcin as a diagnostic biomarker for primary osteoporosis in women. J. Clin. Diagn. Res. 9: RC04-RC07.

Wada T, Nakashima T, Hiroshi N and Penninger JM (2006). RANKL-RANK signaling in osteoclastogenesis and bone disease. Trends Mol. Med. 12: 17-25.http://dx.doi.org/10.1016/j.molmed.2005.11.007

Wang P, Li XT, Sun L and Shen L (2013). Anti-inflammatory activity of water-soluble polysaccharide of Agaricus blazei Murill on ovariectomized osteopenic rats. Evid. Based Complement. Alternat. Med. 2013: 164817.

Genetics and Molecular Research 15 (4): gmr15049169 
Wang YF, Liu WT, Chen CY, Ke HP, et al. (2015). Anti-osteoporosis activity of red yeast rice extract on ovariectomyinduced bone loss in rats. Genet. Mol. Res. 14: 8137-8146. http://dx.doi.org/10.4238/2015.July.27.2

Wei W, Xiao HT, Bao WR, Ma DL, et al. (2016). TLR-4 may mediate signaling pathways of Astragalus polysaccharide RAP induced cytokine expression of RAW264.7 cells. J. Ethnopharmacol. 179: 243-252. http://dx.doi.org/10.1016/j. jep.2015.12.060

Yan H, Xie Y, Sun S, Sun X, et al. (2010). Chemical analysis of Astragalus mongholicus polysaccharides and antioxidant activity of the polysaccharides. Carbohydr. Polym. 82: 636-640. http://dx.doi.org/10.1016/j.carbpol.2010.05.026

Yang B, Xiao B and Sun T (2013). Antitumor and immunomodulatory activity of Astragalus membranaceus polysaccharides in H22 tumor-bearing mice. Int. J. Biol. Macromol. 62: 287-290. http://dx.doi.org/10.1016/j.ijbiomac.2013.09.016

Zeng GF, Zhang ZY, Lu L, Xiao DQ, et al. (2011). Protective effects of Polygonatum sibiricum polysaccharide on ovariectomy-induced bone loss in rats. J. Ethnopharmacol. 136: 224-229.http://dx.doi.org/10.1016/j.jep.2011.04.049

Zhang CZ, Wang SX, Zhang Y, Chen JP, et al. (2005). In vitro estrogenic activities of Chinese medicinal plants traditionally used for the management of menopausal symptoms. J. Ethnopharmacol. 98: 295-300. http://dx.doi.org/10.1016/j. jep.2005.01.033

Genetics and Molecular Research 15 (4): gmr15049169 